\title{
Nietzsche, Darwin e a questão do progresso evolutivo
}

\author{
Nietzsche, Darwin and the problem \\ of evolutionary progress
}

\section{Emmanuel Salanskis Université de Strasbourg, França}

\section{RESUMO}

O presente artigo visa a esclarecer uma dificuldade metodológica que o intérprete da relação Nietzsche-Darwin tem que enfrentar para não cometer um anacronismo neodarwinista. Nietzsche provavelmente nunca leu as obras principais de Darwin, $A$ origem das espécies e $A$ descendência do homem: por isso, os comentadores se interessam pelas fontes secundárias que fundamentaram a avaliação nietzschiana do darwinismo. Em princípio, essa investigação permite comparar o que Nietzsche entendeu por "darwinismo" com a verdadeira teoria de Darwin, a fim de evidenciar possíveis equívocos. Mas em razão da emergência de uma teoria sintética da evolução no século $\mathrm{xx}$, tendemos hoje a assimilar o "verdadeiro Darwin" ao autor da primeira edição de $A$ origem das espécies, publicada em I859. Ora, tal assimilação é discutível absolutamente falando e não podia ser a perspectiva de um leitor normal durante a década de I88o. Pelo contrário, se considerarmos edições ulteriores da obra de Darwin, o que aparecia como um contrassenso de Nietzsche pode revelar-se uma crítica legítima. Essa é a tese que gostaria de defender sobre a questão do progresso evolutivo, alvo crucial do discurso antidarwinista de Nietzsche.

\section{PALAVRAS-CHAVE}

Nietzsche; Darwin; Darwinismo; Evolução; Progresso; Complexidade; Divisão fisiológica do trabalho; Valor.

\begin{abstract}
This paper aims at clarifying a methodological difficulty which any interpreter of the Nietzsche-Darwin relationship must face to avoid committing a Neo-Darwinist anachronism. Nietzsche probably never read Darwin's main works, On the Origin of Species and The Descent of Man: scholars therefore focus on the secondary sources underlying Nietzsche's assessment of Darwinism. In principle, this investigation allows a comparison between what Nietzsche understood by "Darwinism" and Darwin's actual theory, to evidence potential misinterpretations. But because of the emergence of a synthetic theory of evolution during the $20^{\text {th }}$ century, we tend nowadays to assimilate the "true Darwin" to the author of the first edition of On the Origin of Species, published in 1859 . This is questionable absolutely speaking and couldn't be the perspective of a normal reader during the 1880 decade. On the contrary, if we consider later editions of Darwin's book, what appeared as a Nietzschean misconstruction can prove a legitimate criticism. This is the thesis I want to defend on the theme of evolutionary progress, a crucial target of Nietzsche's anti-Darwinist discourse.
\end{abstract}

\section{KEY WORDS}

Nietzsche; Darwin; Darwinism;

Evolution; Progress; Complexity;

Physiological division of labour; Value. 
A relação entre Nietzsche e Darwin é um assunto complexo que suscitou comentários contraditórios na pesquisa recente. $\mathrm{O}$ tema recebeu um tratamento global nas monografias de John Richardson e Dirk Johnson. 'Todavia, ambas defendem interpretações metodologicamente discutíveis, na medida em que usam um conceito de "darwinismo" que, na segunda metade do século XIX, não possuía o sentido unívoco que se costuma supor. Essa polissemia foi bem evidenciada por meu colega do GEN Wilson Frezzatti num artigo de 2009. ${ }^{2}$ Tal indeterminação introduz uma ambiguidade fundamental na questão de saber se Nietzsche era ou não "darwinista", como constatou o mesmo Wilson Frezzatti num estudo estimulante intitulado Nietzsche contra Darwin. ${ }^{3}$ Compartilho com Wilson a conviçção de que a palavra "darwinismo" só tem um poder explicativo limitado, especialmente para analisar o período no qual Nietzsche desenvolveu sua filosofia, ou seja, as décadas de I870 e i880. Na ausência de uma leitura nietzschiana direta de $A$ origem das espécies, o que importa é, antes de tudo, esclarecer o que o próprio Nietzsche entendeu por "darwinismo" e quais fontes secundárias usou para avaliar a teoria de Darwin. ${ }^{4}$

No entanto, essa busca de mediações, ainda que necessária, levou por vezes os comentadores a concluir que Nietzsche se enganou sobre o verdadeiro Darwin. ${ }^{5}$ Porém, a expressão "o verdadeiro Darwin" levanta uma outra dificuldade frequentemente despercebida. Desde a emergência da teoria sintética da evolução, no século xx, a teoria darwiniana tendeu a ser interpretada num sentido neodarwinista. Essa interpretação se apoia principalmente na primeira edição de A origem das espécies, publicada em I859. Com efeito, em 1964, o grande biólogo e historiador da biologia Ernst Mayr sugeriu a ideia paradoxal de que, no caso do livro fundador de Darwin, o texto de referência é a primeira edição, que seria mais autenticamente darwiniana do que as cinco ediçôes ulteriores. ${ }^{6}$ Não vou discutir os argumentos de Mayr aqui. Gostaria apenas de chamar a atenção para um risco de anacronismo que pode decorrer dessa argumentação para os intérpretes da relação NietzscheDarwin. Do ponto de vista de um contemporâneo de Darwin como Nietzsche, o "verdadeiro Darwin" se encontrava na sexta edição, corrigida e aumentada em I876. Isso tem implicaçōes importantes para avaliar

I Richardson, 2004 e Johnson, 2010.

2 Frezzatti, 2009. Conforme lembrado no artigo, a palavra "darwinismo" não foi cunhada pelo próprio Darwin e podia significar, entre outras acepções, o evolucionismo em geral ou a teoria da evolução por seleção natural.

3 Frezzatti, 2014.

4 Ibid., p. I3 e 32.

5 Ibid., p. I04; Richardson, 2004, p. I6; Itaparica, 2011.

6 Darwin, 1964.

7 Darwin, 1876. 
a fidelidade a Darwin da recepção nietzschiana. Podese ilustrar essas implicações com a questão do progresso evolutivo, que é, como se sabe, um alvo crucial do discurso antidarwinista de Nietzsche.

A crítica a uma certa concepção darwinista de progresso atravessa o corpus nietzschiano, com uma extensão e uma intensidade crescentes. Em I878, Humano, demasiado humano já faz ressalvas às explicaçôes do progresso cultural em termos de luta pela existência: Nietzsche considera que "não é o único ponto de vista" relevante. ${ }^{8}$ Ainda naquela época, o filósofo apresenta sua própria hipótese com prudência e sem estender suas objeçōes além do campo antropológico. Mais, dez anos mais tarde, a oposição se tornou mais resoluta no pequeno manifesto "Anti-Darwin" do Crepúsculo dos Ídolos. Doravante, Nietzsche afirma contra a "escola de Darwin", de modo mais geral e categórico, que "as espécies não crescem na perfeição [...]". ' Assim, ao longo de uma década de produção filosófica, podemos considerar como um fato a rejeição nietzschiana do darwinismo enquanto progressionismo.

Um problema interpretativo surge quando levamos em consideração o discurso historiográfico (representado, entre outros, por Peter Bowler e Michael Ruse) segundo o qual Darwin não era realmente progressionista. ${ }^{\text {Io }}$ Se aceitarmos esse discurso, parece que Nietzsche cometeu um contrassenso sobre Darwin ao desenvolver suas objeçôes antiprogressionistas: é, de fato, a opinião de certos estudiosos de Nietzsche. ${ }^{\text {II }}$ Poderíamos sustentar essa hipótese, por exemplo, considerando que Nietzsche confundiu Darwin com um darwinismo vulgarizado. O "darwinismo" do Crepúsculo dos Ídolos não seria nada mais do que o providencialismo darwinista de autores como Charles Richet, que prometeu a vitória irremediável dos fortes e o aperfeiçoamento inexorável das espécies. ${ }^{\mathrm{I2}}$ Contudo, gostaria de evidenciar que a premissa dessa análise ("Darwin não era progressionista") é errônea estritamente falando, justamente por não levar em conta a concepção de progresso defendida a partir da segunda edição de $A$ origem das espécies. Pretendo mostrar que Nietzsche identificou e recusou a concepção darwiniana final de progresso, de modo que, sobre esse assunto específico, a tese do contrassenso é indefensável.

8 Humano, demasiado Humano $₫ 224$, KSA 2.I88. Tradução conforme Rubens Rodrigues Torres Filho (Nietzsche, 1999).

9 Crepúsculo dos Ídolos, "Incursões de um extemporâneo", \$ I4, KSA 6.I20. Tradução conforme Paulo César de Souza (Nietzsche, 2006). A partir de agora indicado como PCs.

IO Bowler, I986, p. 4I; Ruse, I988; Shanahan, 2004, pp. 285-294.

II Ansell Pearson, 1997, p. I05 ss.

I2 Richet, I884, pp. 395-454. 


\section{0 progresso segundo Darwin: uma equação hipotética entre dois conceitos}

Tendo em vista esse objetivo, devo começar por uma análise da concepção darwiniana de progresso. A esse respeito, a reflexão de Darwin é particularmente sutil e não foi suficientemente entendida pela maioria dos leitores, como bem mostra o livro de Timothy Shanahan intitulado A evolução do darwinismo. Remeto em particular à terceira parte do livro, que traça a história dos debates em torno do progresso na biologia evolucionária. ${ }^{\mathrm{I3}}$ Shanahan sustenta que Darwin de fato adotou uma forma de progressionismo a partir de I860, embora de modo hipotético e num sentido específico. A ideia crucial de Darwin consistiu numa aproximação entre dois conceitos de progresso: primeiro, a elevação competitiva, que corresponde a uma melhor adaptação do ponto de vista da seleção natural; e, em seguida, a complexificação orgânica, definida em referência à embriologia comparada de Karl Ernst von Baer e à zoologia de Henri Milne Edwards. A hipótese darwiniana foi que esses dois conceitos coincidem tendencialmente, ou seja, a complexificação seria, em regra geral, uma vantagem adaptativa, que aumentaria as chances de sobrevivência e de reprodução de um organismo. Trata-se de uma tese não trivial, que nos estimula a examinar o processo complexo que levou Darwin a postular tal coincidência. Como explicar a ausência da hipótese em questão na primeira edição da Origem das espécies, bem como o acréscimo trazido pelas edições ulteriores?

Para responder a essa pergunta, devemos ter em mente um problema conceitual. A noção de progresso evolutivo tem três dimensões: ela envolve uma valoração em relação à qual uma coisa é considerada melhor; ela também inclui a ideia de uma mudança em direção ao que é valorado; e, por fim, é preciso que cada melhoramento participe de um processo cumulativo, para que haja realmente evolução progressiva. ${ }^{\mathrm{I}}{ }^{4}$ Pode-se dizer que Darwin tinha uma simpatia ideológica pelos discursos progressionistas do seu tempo. Mas, ao contrário de outros autores menos rigorosos, ele também entendeu a necessidade de um critério transversal de evolução progressiva para justificar essa linguagem. Isso posto, pode-se pensar que ele hesitou entre duas opções, antes de chegar a uma síntese.

A primeira opção era mostrar que a seleção natural já é uma base de comparação transversal entre os organismos. Há textos que parecem apoiar essa leitura, nas seis ediçōes de $A$ origem das espécies que foram publicadas durante a vida do autor. São passagens que evocam uma grande "corrida pela vida" ("the race for life"), como se Darwin falasse de uma única competição evolutiva e como se os

I3 Shanahan, 2004, pp. 173-246.

I4 Ibid., p. 222. 
organismos atuais tivessem sido, coletivamente, os vencedores. Assim, da primeira até a a sexta edição, encontramos a frase seguinte com muito pequenas alterações: "The inhabitants of each successive period in the world's history have beaten their predecessors in the race for life, and are, in so far, higher in the scale of nature". Darwin sugere, por exemplo, que os habitantes atuais do mundo suplantariam os organismos do Eoceno. ${ }^{16}$

No entanto, em se tratando de Darwin, sempre há um outro lado do problema. Um confronto entre os organismos presentes e passados é necessariamente fictício. Darwin acrescentou imediatamente, na primeira edição: "mas não vejo como testar esse tipo de progresso". ${ }^{17}$ Além disso, mesmo uma confrontação imaginária deveria ser equitativa. Eis porque Darwin admitiu uma competição "sob um clima aproximadamente semelhante". Mas para isso o naturalista inglês pressupôs que o clima não tenha sofrido alterações importantes entre os dois períodos considerados. Pois, no caso contrário, a forma passada A e a forma contemporânea в poderiam ser incapazes de viver no mesmo meio ambiente. $\mathrm{O}$ teste da competição direta não teria um resultado claro: o vencedor dependeria da escolha do meio ambiente. Uma outra objeção mais profunda é que todos os organismos não estão em competição direta. De fato, em Darwin, a evolução não é simplesmente linear, pois é um processo de ramificação. A seleção natural produz uma divergência dos caracteres, na medida em que tal diversificação permite ocupar novos nichos ecológicos. ${ }^{18}$ Ora, como comparar dois organismos que divergiram há milhões de anos e que sobreviveram em meios separados? Isso mostra que a vitória na luta pela existência não é um critério realmente sistemático. ${ }^{19}$ Com esse critério, por exemplo, é impossível dizer que o homem seja superior à ameba. ${ }^{20}$

É por essa razão, a meu ver, que Darwin escolheu uma segunda opção para legitimar um progressionismo evolucionista. A partir da segunda edição de $A$ origem das espécies, ele apresentou a luta pela existência como um fator de complexificação orgânica, além da mera adaptação. Cito a definição darwiniana da superioridade evolutiva:

I5 "Os habitantes de cada período sucessivo na história do mundo têm vencido os seus predecessores na corrida pela vida e são, nessa medida, superiores na escala da natureza" (Darwin, I859, p. 345, tradução de nossa responsabilidade).

I6 Ibid., p. 337.

I7 Ibid., tradução de nossa responsabilidade.

I8 Ibid., p. III ss.

I9 Darwin, I876, p. 99; Shanahan, 2004, p. I8I.

20 Aqui, podemos pensar na frase de um personagem de H. G. Wells na Guerra dos mundos, acerca da suposta guerra entre os homens e os marcianos: "It never was a war, any more than there's war between man and ants" ("Nunca foi uma guerra, assim como nunca houve uma guerra entre os homens e as formigas"). 
A melhor definição é, provavelmente, que as formas superiores têm órgãos mais distintamente especializados para diversas funções; e, dado que tal divisão fisiológica do trabalho parece ser uma vantagem para cada ser vivo, nessa medida, a seleção natural tenderá constantemente a tornar as formas ulteriores e mais modificadas superiores aos seus progenitores $[\ldots]^{2.1}$

Darwin reconhece que a tendência descrita sofre exceções. Ele admite, por exemplo, exceçôes estagnantes. São os "fósseis vivos", como o ornitorrinco, que sobreviveram até hoje numa forma pouco modificada, por não serem expostos a uma competição severa. ${ }^{22}$ Além delas, há também exceções regressivas: um novo meio ambiente pode tornar certos órgãos inúteis, o que favorecerá o desaparecimento dessas estruturas supérfluas. ${ }^{23} \mathrm{O}$ exemplo clássico é o dos animais cavernícolas que perderam o uso dos seus olhos. ${ }^{24}$

Contudo, da segunda edição até a sexta, as exceçôes confirmam a regra. Existe uma orientação global na evolução: Darwin chega a afirmar que a seleção natural "conduz inevitavelmente ao avanço gradual da organização da maioria dos seres vivos através do mundo". ${ }^{25}$ É verdade que isso não consiste no mesmo tipo de necessidade que encontramos em Lamarck. Este acreditava numa dinâmica de complexificação inerente à vida, sem exceções, já que a existência atual de formas inferiores se devia a gerações espontâneas. ${ }^{26}$ Em Darwin, a complexificação não foi pensada como uma lei universal, mas antes como uma tendência estatística. Mesmo assim, Darwin fez uma aposta arriscada, pois se trata de uma forma de progressionismo que Stephen Jay Gould, por exemplo, criticou explicitamente num livro intitulado Full House. ${ }^{27}$ Gould lembra que, de um ponto de vista estatístico, não vivemos na "idade dos mamíferos", mas sim na "idade das bactérias". ${ }^{28}$ Nesse sentido, dizer que a maioria dos seres vivos progride em complexidade não comporta nada de evidente. Além disso, Darwin sabia que a complexidade não é

2I Darwin, I860, p. 336, tradução de nossa responsabilidade.

22 Ibid., p. 107.

23 Darwin, I86I, p. I34.

24 Ibid., pp. I55-I56.

25 Darwin, I876, p. 97, tradução de nossa responsabilidade. Assim, o progresso da organização não é mais um "sentimento vago", como na primeira edição, mas sim uma opinião justificada. A variação na formulação é notável entre a edição de 1859 ("that vague yet ill-defined sentiment, felt by many palæontologists, that organisation on the whole has progressed", p. 345) e a edição de I876 ("the common belief held by so many palæontologists, that organisation on the whole has progressed", p. 315).

26 Ibid., p. 98.

27 Gould, 1996.

28 Ibid., p. Io8, trad. Es. 
mensurável na prática. Citando von Baer, ele próprio sublinha a impossibilidade de comparar diferentes tipos de organização: "quem vai decidir se as sépias são superiores às abelhas?”, pergunta o naturalista. ${ }^{29}$

Tampouco a noção de divisão fisiológica do trabalho, que o zoologista Henri MilneEdwards tomou emprestado da economia política, resolveria o problema. Darwin pareceu adotar esse critério nas últimas ediçōes. Mas o pressuposto seria que todos os seres vivos produzem a mesma coisa: como no exemplo econômico da produção de alfinetes, analisado por Adam Smith: a mesma fabricação de alfinetes pode ser organizada com diferentes graus de divisão do trabalho. ${ }^{30}$ Contudo, outros textos darwinianos reconhecem a diversidade funcional que caracteriza o mundo vivo. Não são apenas as estruturas que evoluem, mas também as próprias funções, como deixa claro o texto de I862 sobre a fertilização das orquídeas. ${ }^{3 \mathrm{I}}$ Por isso, a divisão do trabalho também não pode ser um critério suficiente. Por fim, Darwin teve que confessar "a obscuridade do assunto" ${ }^{32}$ Em vista de todos os problemas que ele mencionou sem os resolver, é realmente fascinante que Darwin defenda um progressionismo. Voltarei em conclusão à questão das razões dessa escolha.

\section{A crítica nietzschiana da equação darwiniana}

Mas antes disso, gostaria de mostrar que Nietzsche colocou em questão o progressionismo darwiniano, tal como foi caracterizado na primeira parte do presente artigo.

Para tanto, é preciso estabelecer que Nietzsche conhecia o núcleo da posição de Darwin. Isso pode ser evidenciado à luz das fontes de Nietzsche sobre a teoria darwiniana. Vou citar dois livros que figuram na biblioteca pessoal do filósofo alemão: Descendenzlehre und Darwinismus de Oscar Schmidt, publicado em I873, e Mechanisch-physiologische Theorie der Abstammungslehre de Carl von Nägeli, publicado em I884. Ambos autores apresentam distintamente o aspecto da teoria darwiniana que me interessa.

O livro de Schmidt é uma pequena apresentação da teoria da evolução, escrita por um professor de zoologia na Universidade de Estrasburgo. No capítulo 8, o autor repete a tese progressionista de Darwin: a seleção natural conduz a um aperfeiçoamento gradual, no sentido de uma complexificação e de uma maior divisão do trabalho. Conforme afirma Schmidt: "na luta de todos contra todos

29 Darwin, 1876, p. 308.

30 D'Hombres, 20I2, pp. 5-6 e I2.

3I "Thus throughout nature almost every part of each living being has probably served, in a slightly modified condition, for diverse purposes, and has acted in the living machinery of many ancient and distinct specific forms" (Darwin, I862, p. 348).

32 Darwin, I876, p. 97, tradução de nossa responsabilidade. 
ganham os indivíduos que conseguem alguma vantagem sobre seus congêneres na divisão do trabalho". ${ }^{33}$ Como se vê, é exatamente o critério de Milne-Edwards revisto por Darwin. Ainda segundo Schmidt, a seleção natural designa "o conjunto dos aperfeiçoamentos obtidos na adaptação por meio de especialização": reconhecemos o mesmo critério, com uma formulação mais próxima de von Baer. ${ }^{34} \mathrm{Em}$ outras palavras, Schmidt é claramente darwiniano sobre a questão do progresso. Sutil como Darwin, lembra os limites do progresso evolutivo sublinhados em $A$ origem das espécies: especialmente a possibilidade de uma evolução regressiva e o caráter parcial e relativo de qualquer adaptação.

Passo à obra de Carl von Nägeli, Mechanischphysiologische Theorie der Abstammungslehre. Trata-se de um livro volumoso escrito por um botânico suíço, que defende uma teoria antidarwiniana da evolução. Em particular, Nägeli critica o vínculo entre seleção natural e aperfeiçoamento no pensamento de Darwin. Nägeli quer introduzir uma outra explicação do progresso orgânico, mas vou desconsiderar essa proposta teórica aqui. O que me importa é apenas a exposição do livro acerca de Darwin, que é interessante por duas razões. A primeira é que Nägeli adota exatamente o mesmo conceito de aperfeiçoamento que Darwin. Como lemos na introdução: "Aperfeiçoamento no meu sentido não é nada, senão o progresso em direção a uma estrutura mais complexa e a uma divisão do trabalho maior" ${ }^{35}$ Um segundo interesse é que Nägeli, justamente por ser um adversário dessa concepção, ressalta nitidamente o papel da seleção natural no progressionismo darwiniano. Diz ele que "segundo Darwin, a seleção é necessária; sem ela, um aperfeiçoamento não poderia advir [...] ${ }^{136}$. O fato é que, conforme lembra Nägeli, Darwin não concebe a variação orgânica como um processo orientado. ${ }^{37}$ Trata-se de uma variabilidade aleatória, sem direção preferencial, que não poderia produzir um avanço se ela não fosse naturalmente selecionada. Nägeli deixa esse ponto muito claro. E, neste caso, temos anotações de leitura de Nietzsche nas páginas relevantes do seu exemplar. ${ }^{38}$

Podemos assim concluir que Nietzsche conhecia a ossatura do progressionis-

33 Schmidt, I873, p. I74, tradução de nossa responsabilidade.

34 Ibid., p. I75, tradução de nossa responsabilidade.

35 Nägeli, I884, p. I3, tradução de nossa responsabilidade.

36 Ibid, p. 285, tradução de nossa responsabilidade.

37 Ibid., p. 286.

38 No exemplar pessoal de Nietzsche foi sublinhado, em particular, a frase seguinte: "aber [die Concurrenz] ist gänzlich ohne Einfluss auf das Zustandekommen alles Vollkommneren und besser Angepassten" (i.e.: "mas [a concorrência] é completamente desprovida de influência sobre a emergência de tudo o que é mais perfeito e melhor adaptado"). Para consultar essas anotaçóes no site Internet da biblioteca Anna Amalia de Weimar, cf. https://haab-digital.klassik-stiftung.de/viewer/image/I2I728284X/I56/. 
mo darwiniano, mesmo sem ter lido $A$ origem das espécies.

Isso não deveria ser uma surpresa, na medida em que Nietzsche justamente atacou essa concepção em sua obra publicada e seus fragmentos póstumos. Já mencionei a incursão "AntiDarwin" do Crepuisculo dos Ídolos. Quando consideramos esse texto mais atentamente, vemos que Nietzsche não contestou a mera existência da seleção natural. Antes, ele fez duas objeções. A primeira concerne à suposta onipresença da seleção no mundo vivo, que tem a ver com o malthusianismo de Darwin: em razão de um desequilíbrio recorrente entre o crescimento geométrico das populações e o crescimento aritmético dos recursos, a natureza seria, de modo geral, caracterizada por uma indigência e uma concorrência geradores de pressão seletiva. Sabese que Nietzsche rejeitou essa visão, mas vou deixar essa primeira objeção de lado. O que me importa aqui é a segunda objeção: quando a luta pela existência ocorre, pois, "de fato, ela ocorre", "infelizmente ela resulta no contrário do que deseja a escola de Darwin". ${ }^{99} \mathrm{O}$ resultado não é um progresso, nem uma complexificação, mas sim o que Nietzsche chama, com provocação, de vitória dos fracos.

Vou analisar essa ideia paradoxal, mas antes disso, é preciso destacar que Nietzsche pode subscrever uma valorização da complexidade. Por exemplo, um dos dois fragmentos "AntiDarwin" de I888 afirma que "o tipo superior apresenta uma complexidade incomparavelmente maior, — uma maior soma de elementos coordenados". ${ }^{40}$ Em outros textos, Nietzsche critica os "homens-fragmentos" e elogia, pelo contrário, os homens completos que encarnam uma síntese de impulsos contrários. ${ }^{41}$ Nesse sentido, a axiologia nietzschiana é, também ela, uma axiologia da complexidade: entre Darwin e Nietzsche, o desacordo não concerne meramente aos valores. Há uma divergência entre eles sobre o processo de emergência da complexidade. Nietzsche simplesmente não acredita na equação darwiniana entre mais adaptado e mais complexo.

É verdade que o aspecto propriamente evolucionista da argumentação de Nietzsche ficou num estado embrionário, inclusive em I888. Nietzsche não era naturalista e refletia principalmente sobre as culturas humanas. Aliás, um fragmento de 1888 reivindica esse ponto de partida antropológico:

O que mais me surpreende, diante do espetáculo global dos grandes destinos humanos, é ver sempre ante meus olhos o contrário do que hoje Darwin com sua escola vê ou quer ver: a seleção a favor dos mais fortes,

39 Crepúsculo dos Ídolos, "Incursões de um extemporâneo", \$ I4, KSA 6.I20, tradução de PCS.

40 Fragmento Póstumo I4 [133] da primavera de I888, KSA I3.317. Tradução conforme Wilson Antonio Frezzatti Jr. (Nietzsche, 20Io), ligeiramente modificada.

4I Fragmentos Póstumos 27 [I6] do verão/outono de I884, KSA II.278, e I [4] do outono de I885/primavera de I886, KSA I2.II. 
dos melhores dotados, o progresso da espécie. É precisamente o contrário que se toca com as mãos: o apagamento dos casos felizes, a inutilidade dos tipos mais elevados, a inevitável tomada de poder pelos tipos médios ou mesmo abaixo da média. Supondo que não nos seja indicada a razão do homem ser a exceção entre as criaturas, eu prefiro manter o preconceito de que a escola de Darwin se enganou em toda parte. ${ }^{42}$

Aqui, a lógica de reflexão é bastante clara. $\mathrm{O}$ progressionismo darwiniano seria errado no que diz respeito ao homem e Darwin não poderia explicar satisfatoriamente porque o homem seria uma exceção. Conclusão: a tese de Darwin é errada, de modo geral. Mas o mais interessante é o processo axiológico que Nietzsche teoriza na história humana, do ponto de vista do seu próprio sistema de valores. $\mathrm{Na}$ esfera antropológica, uma luta pela existência mais intensa provoca uma mediocrização. Pois não são os indivíduos complexos, independentes, cultivados, senhores dos seus impulsos, que ganham a batalha pela vida, numa situação de empobrecimento geral. Pelo contrário, a complexidade humana não é imediatamente útil. Ela tem, para Nietzsche, uma dimensão quase suntuária, que vai além da adaptação a uma competição pontual.

Uma outra fonte evolucionista ligada a esse discurso é o livro de Francis Galton, Inquiries into Human Faculty and its Development. ${ }^{43}$ Com efeito, a partir de i884, Galton convenceu definitivamente Nietzsche de que o homem é um animal de rebanho. Segundo o primo de Darwin, a maior parte dos homens têm uma natureza gregária, consequência de uma longa seleção social a desfavor dos indivíduos mais independentes. ${ }^{44}$ Galton comparou o homem dos tempos bárbaros com os bois selvagens que ele pôde ver na África do Sul. ${ }^{45}$ Esses rebanhos selvagens são, de fato, muito mais gregários do que os rebanhos domésticos: na maioria esmagadora dos indivíduos, uma separação com o resto do rebanho, mesmo por alguns instantes, provoca uma crise de pânico incontrolável..$^{46}$ Ora, não é difícil explicar esse fenômeno pela seleção natural, uma vez que os predadores atacam de preferência os animais isolados. Mas Galton sugere que exista um análogo humano desse gregarismo, cultivado pelas circunstâncias e herdado até hoje. ${ }^{47}$ Nietzsche concordou em grande parte a esse respeito. Em Para além de Bem e Mal, também deplorou o triunfo do homem de rebanho na Europa

42 Fragmento Póstumo I4 [I23] da primavera de I888, KSA I3.303, tradução de nossa responsabilidade.

43 Galton, 1883.

44 Ibid., pp. 68-82.

45 Ibid., pp. 78-79.

46 Ibid., p. 72.

47 Ibid., pp. 69 e 80-8I. 
democrática: hoje em dia, é o homem que se vangloria de ser "a única espécie humana autorizada" [die einzig erlaubte Art Mensch], segundo o $\$ 199 .{ }^{48}$ Nesse contexto, o problema axiológico é que a maioria gregária reprime os grandes indivíduos, capazes de originalidade e de solidão. Isso lança luz sobre o paradoxo antidarwinista famoso do Crepúsculo dos Ídolos: "os fracos sempre tornam a dominar os fortes". ${ }^{49}$ Tal dominação invertida é esclarecida pela indicação que segue: "- pois [os fracos] são em maior número". De toda evidência, Nietzsche ressignifica a força e a fraqueza a partir de sua antropologia filosófica: o fraco é o homem de rebanho, o forte é o grande homem. Mas Nietzsche também fez uma aposta arriscada ao opor esse tipo de argumento a Darwin. Pode-se perguntar se a oposição entre gregarismo e individualismo realmente constitui uma chave de leitura evolucionária geral, na medida em que o simples conceito de gregarismo não parece ter sentido fora da esfera dos animais sociais.

\section{Conclusão}

Chego à conclusão dessa breve apresentação. Nietzsche tem razão, a meu ver, quando acusa Darwin de defender um progressionismo sem argumentos convincentes. Vimos que o próprio Darwin menciona objeçōes que inviabilizam a sua posição oficial. Isso mostra que o naturalista ficou preso a um contexto cultural progressista, cuja genealogia Nietzsche tentou esboçar, especialmente no $\$ 349$ de A gaia ciência. Assim, se o progressismo é uma "ideia moderna" no sentido de Para além de bem e mal, também significa que é uma ideia moral.

Mas talvez tenha um perspectivismo mais profundo suscetível de reconciliar Nietzsche e Darwin. No "Notebook B", um caderno póstumo de I837 ou I838, Darwin escreveu: "é absurdo falar de superioridade de um animal sobre um outro. - Nós consideramos como os mais elevados aqueles em que as faculdades intelectuais [ou] a estrutura cerebral são mais desenvolvidas. - Uma abelha certamente faria a mesma coisa com os instintos —.${ }^{\circ}$ Em outras palavras, Darwin estava ciente do caráter perspectivo de todas as hierarquizações. Nesse sentido, a valorização da complexidade não deixa de ser antropocêntrica: poderíamos imaginar uma valorização inversa da simplicidade, do ponto de vista de que a complexificação seria um declínio. E, conforme salienta Nietzsche, a simples crença no progresso também é uma perspectiva particular que traduz as preferências

48 Para além de Bem e Mal \$ I99, KSA 5.II9-I20, tradução de nossa responsabilidade.

49 Crepúsculo dos Ídolos, "Incursões de um extemporâneo", \ I4, KSA 6.I2O, tradução de PCS.

50 "It is absurd to talk of one animal being higher than another. - We consider those, when the intellectual faculties [/] cerebral structure most developed, as highest. - A bee doubtless would when the instincts were - " (Darwin, I837-I838, p. 74, tradução de nossa responsabilidade). 
e as condiçôes de vida de um determinado tipo de organismo. Contudo, não é possível escapar completamente a tal "perspectivocentrismo". O relativismo não é uma opção para Nietzsche. Temos que elaborar uma axiologia crítica, uma hierarquia do nosso ponto de vista, sabendo que o progresso nunca será uma realidade meramente objetiva.

\section{Bibliografia}

Ansell Pearson, K. Viroid Life. Perspectives on Nietzsche and the Transhuman Condition. Oxon/New York: Routledge, 1997.

Bowler, P. J. Theories of Human Evolution: A Century of Debate, 1844-1944. Baltimore: Johns Hopkins University Press, 1986.

Campioni, G., D’iorio, P., Fornari, M. Cr., Fronterotta, Fr., Orsucci, A. (Hrsg.). Nietzsches persönliche Bibliothek. Berlin: de Gruyter, 2003.

DARWIN, Ch. Notebook B [Transmutation of species (1837-1838)]. Transcribed by Kees Rookmaaker. In: Darwin Online, http://darwin-online.org.uk/content/ frameset?itemID=CUL-DAR121.-\&viewtype=text\&pageseq $=1$.

DARWIN, Ch. On the Origin of Species by means of Natural Selection, or the Preservation of Favoured Races in the Struggle for Life. London: John Murray, I859.

DARWIN, Ch. On the Origin of Species by means of Natural Selection, or the Preservation of Favoured Races in the Struggle for Life. London: John Murray, I86o.

DARWIN, Ch. On the Origin of Species by means of Natural Selection, or the Preservation of Favoured Races in the Struggle for Life. London: John Murray, I86I.

DARWIN, Ch. The Origin of Species by Means of Natural Selection, or the Preservation of Favoured Races in the Struggle for Life. London: John Murray, 1876.

Darwin, Ch. On the Origin of Species. With an introduction by Ernst Mayr. Cambridge: Harvard University Press, 1964 (facsimile of the first edition, 1859).

DARWIN, Ch. On the Various Contrivances by Which British and Foreign Orchids Are Fertilised by Insects, and on the Good Effects of Intercrossing. London: John Murray, I862.

Dennett, D. Darwin's Dangerous Idea. Evolution and the Meanings of Life. London/ New York/Ringwood/Toronto/Auckland: Penguin Books, 1996.

D'Hombres, E. "The 'Division of Physiological Labour': The Birth, Life and Death of a Concept". In: Journal of the History of Biology, vol. 45, n' I, 20I2, pp. 3-3I.

Frezzatti JR., W. A. "Os sentidos do darwinismo". In: Temas \& Matizes, nº I5, 2009, pp. 5568.

Frezzatti Jr., W. A. Nietzsche contra Darwin, São Paulo: Edições Loyola, 2014.

Galton, Fr. Inquiries into Human Faculty and its Devlopment. London: Macmillan and Co., I883.

Gould, S. J. Full House. The Spread of Excellence from Plato to Darwin. New York: Harmony Books, 1996. 
ItAPARICA, A. L. M. "Darwin e Nietzsche: natureza e moralidade". In: BarrenecheA, M. A., Feitosa, C., Pinheiro, P., Suarez, S. (Org.). Nietzsche e as ciências. Rio de Janeiro: 7 Letras, 20II, pp. 60-70.

Johnson, D. Nietzsche's Anti-Darwinism. Cambridge: Cambridge University Press, 2010.

NäGELI, C. (von). Mechanisch-physiologische Theorie der Abstammungslehre. München/Leipzig: R. Oldenbourg, I884.

Nietzsche, Fr. Sämtliche Werke. Kritische Studienausgabe in Is Bänden. Hrsg. von G. Colli und M. Montinari. Berlin/New York: de Gruyter, 1980 [= KSA].

Nietzsche, Fr. Obras incompletas. Trad. Rubens Rodrigues Torres Filho. São Paulo: Editora Nova Cultural, I999.

Nietzsche, Fr. Crepuisculo dos Ídolos. Trad. Paulo César de Souza. São Paulo: Companhia das Letras, 2006.

Nietzsche, Fr. "Os fragmentos póstumos sobre Darwin". Trad. Wilson Antonio Frezzatti Jr. In: Estudos Nietzsche, Curitiba, v. I, n. 2, jul./dez. 2010, pp. 403-419.

Richardson, J. Nietzsche's New Darwinism. Oxford/New York: Oxford University Press, 2004.

Richet, Ch. L'Homme et l'intelligence. Fragments de physiologie et de psychologie. Paris: Félix Alcan, 1884 .

Ruse, M. "Molecules to Man: Evolutionary Biology and Thoughts of Progress". In: Nitecki, M. (Ed.). Evolutionary Progress. Chicago: University of Chicago Press, 1988, pp. 97126.

Sснмidt, O. Descendenzlehre und Darwinismus. Leipzig: F. A. Brockhaus, I873.

Shanahan, T. The Evolution of Darwinism. Selection, Adaptation, and Progress in Evolutionary Biology. Cambridge: Cambridge University Press, 2004. 